\title{
Identification of MicroRNAs Regulated by Activin A in Human Embryonic Stem Cells
}

\author{
Zong-Yun Tsai, ${ }^{1,2}$ Sher Singh, ${ }^{3}$ Sung-Liang Yu, ${ }^{4}$ Li-Pin Kao, ${ }^{5}$ Bo-Zhi Chen, ${ }^{5}$ \\ Bing-Ching Ho, ${ }^{4}$ Pan-Chyr Yang, ${ }^{6}$ and Steven Shoei-Lung $\mathrm{Li}^{2,5 *}$ \\ ${ }^{1}$ Department of Medicinal and Applied Chemistry, College of Life Sciences, Kaohsiung Medical University, Kaohsiung \\ 807, Taiwan \\ ${ }^{2}$ Stem Cell Laboratory, Center of Excellence for Environmental Medicine, Kaohsiung Medical University, Kaohsiung \\ 807, Taiwan \\ ${ }^{3}$ Department of Life Science, College of Science, National Taiwan Normal University, Taipei 116, Taiwan \\ ${ }^{4}$ Department of Clinical Laboratory Sciences and Medical Biotechnology, National Taiwan University College of \\ Medicine, Taipei 100, Taiwan \\ ${ }^{5}$ Graduate Institute of Medicine, College of Medicine, Kaohsiung Medical University, Kaohsiung 807, Taiwan \\ ${ }^{6}$ Department of Internal Medicine, National Taiwan University College of Medicine, Taipei 100, Taiwan
}

\section{ABSTRACT}

Human embryonic stem (hES) cells have the capacities to propagate for extended periods and to differentiate into cell types from all three germ layers both in vitro and in vivo. These characteristics of self-renewal and pluripotency enable hES cells having the potential to provide an unlimited supply of different cell types for tissue replacement, drug screening, and functional genomics studies. The hES-T3 cells with normal female karyotype cultured on either mouse embryonic fibroblasts (MEF) in hES medium (containing $4 \mathrm{ng} / \mathrm{ml} \mathrm{bFGF}$ ) (T3MF) or feeder-free Matrigel in MEF-conditioned medium (supplemented with additional $4 \mathrm{ng} / \mathrm{ml} \mathrm{bFGF}$ (T3CM) were found to express very similar profiles of mRNAs and microRNAs, indicating that the unlimited self-renewal and pluripotency of $\mathrm{hES}$ cells can be maintained by continuing culture on these two conditions. However, the expression profiles, especially microRNAs, of the hES-T3 cells cultured on Matrigel in hES medium supplemented with $4 \mathrm{ng} / \mathrm{ml} \mathrm{bFGF}$ and $5 \mathrm{ng} / \mathrm{ml}$ activin A (T3BA) were found to be different from those of T3MF and T3CM cells. In T3BA cells, four hES cell-specific microRNAs miR-372, miR-302d, miR-367, and miR-200c, as well as three other microRNAs miR-199a, miR-19a, and miR-217, were found to be up-regulated, whereas five miRNAs miR-19b, miR-221, miR-222, let-7b, and let-7c were down-regulated by activin A. Thirteen abundantly differentially expressed mRNAs, including NR4A2, ERBB4, CXCR4, PCDH9, TMEFF2, CD24, and COX6A1 genes, targeted by seven over-expressed miRNAs were identified by inverse expression levels of these seven microRNAs to their target mRNAs in T3BA and T3CM cells. The NR4A2, ERBB4, and CXCR4 target genes were further found to be regulated by EGF and/or TNF. The 50 abundantly differentially expressed genes targeted by five under-expressed miRNAs were also identified. The abundantly expressed mRNAs

Abbreviations used: hES, human embryonic stem cells; MEF, mouse embryonic fibroblasts; miRNAs, microRNAs; T3MF, hES-T3 cells cultured on MEF; T3CM, hES-T3 cells cultured on Matrigel gel in MEF-conditioned medium; T3BA, hES-T3 cells cultured on Matrigel gel in hES medium supplemented with both $4 \mathrm{ng} / \mathrm{ml} \mathrm{bFGF}$ and $5 \mathrm{ng} / \mathrm{ml}$ activin A.

Authors' contributions: ZYT cultured and characterized T3MF, T3CM, and T3BA cells, as well as did part of data analyses. SS did bioinformatic analyses. S-LY supervised the determination of both miRNAs and mRNAs. L-PK prepared RNA samples. BZC maintained T3MF cells. BCH did luciferase assay. PCY directed the Microarray Core Facility for Genomic Medicine of National Taiwan University College of Medicine where the analyses of miRNAs and mRNAs were done. SSLL designed the experiments, analyzed results, and wrote the manuscript.

Database and accession number: The original data obtained from Affymetrix human genome U133 plus 2.0 GeneChip have been deposited to NCBI database, and the GEO series number is GSE16910.

Zong-Yun Tsai and Sher Singh contributed equally to this work.

The authors declare no competing financial interests.

Additional Supporting Information may be found in the online version of this article.

Grant sponsor: National Science Council of Taiwan; Grant number: NSC-95/96/97-3112-B-037-02; Grant sponsor: Center of Excellent for Environmental Medicine Project; Grant number: KMU-EM-97-1.3c.

*Correspondence to: Steven Shoei-Lung Li, PhD, Graduate Institute of Medicine, College of Medicine, Kaohsiung Medical University, Kaohsiung 807, Taiwan. E-mail: lissl@kmu.edu.tw

Received 9 July 2009; Accepted 21 September 2009 • DOI 10.1002/jcb.22385 • (c) 2009 Wiley-Liss, Inc.

Published online 2 November 2009 in Wiley InterScience (www.interscience.wiley.com). 
in T3BA and T3CM cells were also analyzed for the network and signaling pathways, and roles of activin A in cell proliferation and differentiation were found. These findings will help elucidate the complex signaling network which maintains the self-renewal and pluripotency of hES cells. J. Cell. Biochem. 109: 93-102, 2010. @ 2009 Wiley-Liss, Inc.

\section{KEY WORDS: HUMAN EMBRYONIC STEM CELLS; EXPRESSION PROFILES; mRNAs; microRNAs; miRNA TARGETS}

$\mathrm{H}$ uman embryonic stem (hES) cells are derived from the inner cell mass of blastocysts. These hES cells are capable of unlimited self-renewal and maintain pluripotency in vitro to differentiate into all three germ layers endoderm, mesoderm, and ectoderm [Thomson et al., 1998; Guhr et al., 2006]. Thus, hES cells have potential applications in regenerative medicine and serve as model to study human molecular embryogenesis [Wobus and Boheler, 2005]. The proliferation of undifferentiated hES cells can be maintained on either mitotically inactivated mouse embryonic fibroblasts (MEF) as feeder or Matrigel-coated plastic surfaces in MEF-conditioned medium [Xu et al., 2001]. Activin A was previously reported to be necessary and sufficient for the maintenance of self-renewal and pluripotency of hES cells in long-term feeder- and serum-free culture [Xiao et al., 2006]. It would be of interest to compare the gene expression profiles of these undifferentiated hES cells grown under these three different conditions in order to better understand their common molecular mechanisms of unlimited self-renewal and pluripotency.

Recently, microRNAs (miRNAs) have been shown to play important roles in mammalian embryo development and cell differentiation. Mammalian genomes encode many hundreds of miRNAs, which are predicted to regulate negatively expression of as many as 30\% of protein-coding genes [Bartel, 2004; Griffiths-Jones et al., 2006]. The impact of miRNAs on protein output was recently shown that although some targets were repressed without detectable changes in mRNA levels, those translationally repressed by more than a third also displayed detectable mRNA destabilization, and, for the more highly repressed targets, mRNA destabilization usually comprised the major component of repression [Baek et al., 2008; Selbach et al., 2008]. Although the biological functions of most miRNAs remain to be elucidated, some miRNAs appear to participate in determination of cell fate, in pattern formation in embryonic development, and in control of cell proliferation, cell differentiation, and cell apoptosis in animals [John et al., 2004; Alvarez-Garcia and Miska, 2005; Kloosterman and Plasterk, 2006]. In human and mouse, several ES cell-specific miRNAs had been previously reported [Houbaviy et al., 2003; Suh et al., 2004; Laurent et al., 2008], and these miRNAs were shown to play crucial roles in ES cell differentiation, lineage specification, and organogenesis, especially neurogenesis and cardiogenesis [Chen et al., 2007].

In our laboratories, five hES cell lines had been derived [Li et al., 2006], and 58 mRNAs targeted by hES cell-specific miRNAs were recently identified [Li et al., 2009]. In this investigation, both miRNA and mRNA expression profiles from the hES-T3 cells grown on $\underline{\mathrm{MEF}}$ feeder (T3MF), feeder-free Matrigel in MEF-conditioned medium (T3CM) and in hES medium (containing $4 \mathrm{ng} / \mathrm{ml}$ bFGF) supplemented with $5 \mathrm{ng} / \mathrm{ml}$ activin A (T3BA) were quantitatively determined and compared. The miRNA and mRNA expression profiles of T3MF and T3CM cells were found to be very similar.
However, the miRNA and mRNA expression profiles of T3BA cells were very different from those of T3MF and T3CM cells. Furthermore, expression of several miRNAs was shown to be either up- or down-regulated by activin A, and their target mRNAs identified.

\section{MATERIALS AND METHODS}

\section{HUMAN EMBRYONIC STEM CELL CULTURE}

hES cell line hES-T3, which is one of the five hES cell lines derived with institutional review board approval from preimplantation embryos donated at IVF clinics in Taiwan [Li et al., 2006], exhibits normal female karyotype (46, XX), and it has been continuously cultured on mitomycin $\mathrm{C}(10 \mu \mathrm{g} / \mathrm{ml})$ mitotically inactivated MEF feeder in hES medium under $5 \% \mathrm{CO}_{2}$ at $37^{\circ} \mathrm{C}$ and underwent freezing/thawing processes. The hES culture medium consisted of DMEM/F12 (1:1, GIBC0) supplemented with 20\% KSR (Invitrogen), $1 \%$ non-essential amino acids, $1 \mathrm{mM}$ L-glutamine, $0.1 \mathrm{mM} \beta$ mercaptoethanol, and $4 \mathrm{ng} / \mathrm{ml}$ human basic fibroblast growth factor (bFGF; Life Technologies). Routine passages of hES-T3 cells every 57 days were done with collagenase (type IV, $1 \mathrm{mg} / \mathrm{ml}$, Invitrogen) treatment and mechanical scrape. The hES-T3 cells grown on $\underline{\mathrm{MEF}}$ feeder were designated as T3MF.

The MEF cells were cultured in MEF medium overnight, and the mitotically inactivated MEF were maintained in hES medium containing $4 \mathrm{ng} / \mathrm{ml} \mathrm{bFGF}$. After $24 \mathrm{~h}$, the MEF-conditioned medium was collected and filtered through $0.2 \mu \mathrm{m}$ membrane (PN4612, Pall Life Sciences) as previously described [Xu et al., 2001]. The culture dish was coated with Matrigel diluted with DMEM/F12 (1:30) overnight at $4^{\circ} \mathrm{C}$. The BD Matrigel ${ }^{\mathrm{TM}}$ (Matrix 354234) is the manufacturer's Trademark for extracellular matrix extracted from the Engelbreth-Holm-Swarm tumor. The hES-T3 cells grown on feeder-free Matrigel-coated dish in MEF-conditioned medium (with additional $4 \mathrm{ng} / \mathrm{ml} \mathrm{bFGF}$ ) were designated as T3CM.

The hES-T3 cells were grown on feeder-free Matrigel-coated dish in hES medium (containing $4 \mathrm{ng} / \mathrm{ml}$ bFGF) supplemented with $5 \mathrm{ng} /$ $\mathrm{ml}$ activin A (human recombinant activin A expressed and derived in $\mathrm{CHO}$ cells, R\&D Systems), and these cells were designated as T3BA. Since activin A was previously reported to be necessary and sufficient for the maintenance of self-renewal and pluripotency of hES cells in long-term feeder- and serum-free culture [Xiao et al., 2006], the hES-T3 cells were also grown on feeder-free Matrigel in hES medium (without bFGF) supplemented with 5, 10, and $25 \mathrm{ng} / \mathrm{ml}$ activin A.

\section{STAINING OF OCT4 (POU5F1) AND NANOG}

T3MF, T3CM, and T3BA colonies were fixed by 4\% paraformaldehyde and permeabilized using 0.5\% Triton X-100 in the culture dishes. The immunostaining with rabbit polyclonal antibodies 
against human OCT4 and NANOG (Santa Cruz Biotechnology) were detected with goat anti-rabbit IgG as described previously [Li et al., 2009].

\section{EXTRACTION OF TOTAL RNAs}

Total RNAs from approximately $1 \times 10^{6}$ cells on $10 \mathrm{~cm}$ plate were extracted using TRIZOL reagent, and the same total RNAs from each sample were used for both mRNA microarray analysis and miRNA quantification.

\section{mRNA MICROARRAY ANALYSIS}

The mRNA profilings of T3MF, T3CM, and T3BA cells were analyzed using Affymetrix Human Genome U133 plus 2.0 GeneChip according to the Manufacturer's protocols (Santa Clara, CA, http://www.affymetrix.com) by the Microarray Core Facility of National Research Program for Genomic Medicine of National Science Council in Taiwan. This Affymetrix GeneChip contains 54,675 probe sets to analyze the expression levels of 47,400 transcripts and variants, including 38,500 well-characterized human genes. GeneChips from the hybridization experiments were read by the Affymetrix GeneChip scanner 3000, and raw data were processed using GC-RMA algorithm. The raw data were also analyzed by GeneSpring GX software version 7.3.1 (Silicon Genetics, Redwood City, CA, http://www.chem.agilent.com). It may be noted that Affymetrix GeneChip expression analysis can be used as a stand-alone quantitative comparison, since the correlation between Affymetrix GeneChip results and TagMan RTqPCR results was shown in a good linearity of $\mathrm{R}^{2}=0.95$ by the MicroArray Quality Control Study, a collaborative effort of 137 scientists led by the US-FDA [Canales et al., 2006; Shi et al., 2006].

\section{QUANTIFICATION OF miRNAs}

The expression levels of 250 human miRNAs from T3MF, T3CM, and T3BA cells were determined using the TaqMan MicroRNA Assays (Applied Biosystems, Foster City, CA, http://www.appliedbiosystems.com) [Chen et al., 2005; Liang et al., 2007]. The detailed procedure for miRNA quantification was described previously [Li et al., 2009].

\section{TARGET IDENTIFICATION OF miRNAs}

Target genes of miRNAs were predicted using the TargetCombo open source software (http://www.diana.pcbi.upenn.edu/cgi-bin/miRGen/v3/Targets.cgi) which predicts targets by the union of miRanda (http://microrna.org), PicTar (4-way, http://pictar.bio.nyu.edu/) and TargetScanS (http://www.targetscan.org/) with a cut-off $P$-value less than 0.05 [Sethupathy et al., 2006]. The putative targets of miRNAs were identified by inverse expression levels between miRNAs and their target mRNAs [Bagga et al., 2005; Farh et al., 2005; Lim et al., 2005; Stark et al., 2005; Sood et al., 2006; Baek et al., 2008; Selbach et al., 2008; Li et al., 2009]. The expression levels of the mRNAs targeted by miRNAs in T3CM and T3BA cells were analyzed by the Volcano plot using parametric test and Benjamini-Hochberg false discovery rate for multiple testing correction. The differentially expressed genes were defined by fold-changes of more than 3 and a $P$-value cut-off of 0.05 .

\section{LUCIFERASE ASSAY}

The full-length $3^{\prime}$-UTR of NR4A2 and the truncated $3^{\prime}$-UTR of ERBB4 genes were PCR-amplified from cDNA of HEK293T cells (primer sequences: NR4A2 F5'-gcTCTAGA gacctcctccaagcacttcaaaggaactgg- $3^{\prime}$, NR4A2 R5'-ccAAGCTT ttcatttacatggtttattgttgtaaacatta-3', ERBB4 F5'-gcTCTAGA gctcagttgtggttttttaggtggagag$3^{\prime}$ and ERBB4 R5'-cgACGCGT ccctttacttggagactcatctctgtcat-3'). All of PCR fragments were cloned into pMIR-reporter luciferase vector (Ambion). The precursors of miR-372, miR-302d, miR-19a, and miR-217 were generated by PCR-based ligation and constructed into pSilencer vector (Ambion) with BamHI and HindIII. All transfections were carried out in triplicate in 96-well plates. HEK293T cells $\left(1 \times 10^{4}\right)$ were seeded $24 \mathrm{~h}$ prior to transfection. The luciferase reporter constructs and the Renilla luciferase control vector (pRL-TK Vector; Promega) were co-transfected into cells with the pSilencer vector containing miRNAs or negative control sequence by lipofectamine 2000 (Invitrogen). After $48 \mathrm{~h}$ incubation the DualGlo luciferase substrate (Promega) was added to each well and the luminescent signals were measured by Victor ${ }^{3}$ multilabel counter (PerkinElmer) according to the manufacturer's instructions. The activity of Renilla luciferase was used as an internal control to normalize transfection efficiency [Mayr et al., 2007; Li et al., 2009].

\section{ANALYSES OF NETWORK AND SIGNALING PATHWAYS}

The abundantly expressed mRNAs of T3BA and T3CM cells were analyzed for network and signaling pathways by using MetaCore Analytical Suite (GeneGo, Inc., St. Joseph, MI). The MetaCore includes a curated database of human protein interaction and metabolism, and thus it is useful for analyzing a cluster of genes in the context of regulatory network and signaling pathways. The target genes of miRNAs expressed highly in T3BA cells were also analyzed using Ingenuity Pathway Analysis (IPA) (https://analysis. ingenuity.com) for their involvements in the network and signaling pathways.

\section{RESULTS}

\section{CHARACTERIZATION OF T3MF, T3CM, AND T3BA CELLS}

hES cell line hES-T3 with normal female karyotype $(46, \mathrm{XX})$ was established as previously described [Li et al., 2006]. The hES-T3 cells (passage 36) were cultured on MEF feeder (T3MF) in hES medium (containing $4 \mathrm{ng} / \mathrm{ml} \mathrm{bFGF)} \mathrm{and} \mathrm{feeder-free} \mathrm{Matrigel} \mathrm{in} \mathrm{MEF-}$ conditioned medium with additional $4 \mathrm{ng} / \mathrm{ml} \mathrm{bFGF}$ (T3CM) for 14 and 12 more passages, respectively. The T3MF and T3CM cells were stained positively for OCT4 and NANOG (Supplementary Fig. S1), indicating that both $\mathrm{T} 3 \mathrm{MF}$ and $\mathrm{T} 3 \mathrm{CM}$ cell populations contained very high proportions of undifferentiated hES cells. When hES-T3 cells were grown on feeder-free Matrigel in hES medium (without bFGF) supplemented with 5, 10, and $25 \mathrm{ng} / \mathrm{ml}$ activin A, many cells around the edges, as well as the center, of colonies differentiated into fibroblast-like cells with much less staining of OCT4 and NANOG, and these cells were able to proliferate only two more passages (data not shown). However, the hES cells cultured on feeder-free Matrigel in hES medium containing both $4 \mathrm{ng} / \mathrm{ml} \mathrm{bFGF}$ and $5 \mathrm{ng} / \mathrm{ml}$ activin A were able to proliferate for seven more passages, and most of these 
T3BA cells were stained positively for OCT4 and NANOG (Supplementary Fig. S1).

\section{EXPRESSION PROFILING OF mRNAs}

The genome-wide mRNA expression of T3MF, T3CM, and T3BA cells was determined using Affymetrix human genome U133 plus 2.0 GeneChip. The original data have been deposited to NCBI database, and the GEO series number is GSE16910. The average values of expressed mRNAs from T3MF, T3CM, and T3BA cells were compared by scatter plots (Fig. 1A,B). The Pearson correlation coefficient of $\mathrm{R}^{2}=0.9934$ between T3MF and T3CM cells indicates their very similar expression profiles of mRNAs (Fig. 1A), and only 49 and 17 genes were found to be abundantly (more than threefold of overall mean) differentially (more than threefold of changes) expressed in T3MF and T3CM cells, respectively (Supplementary Table SIA, B). The correlation value of $\mathrm{R}^{2}=0.8285$ between T3BA and T3CM cells suggests less similarity between their mRNA profiles (Fig. 1B), and 589 and 58 genes were abundantly differentially expressed in T3BA and T3CM cells, respectively (Supplementary Table SIC, D).

\section{EXPRESSION PROFILING OF miRNAs}

The expression profiles of 250 human miRNAs in T3MF, T3CM, and T3BA cells were quantitated using TaqMan microRNA Assays as described previously [Chen et al., 2005; Liang et al., 2007; Li et al., 2009], and the expression level of each miRNA was indicated as folds over U6 snRNA. The average values of triplicate analyses for 250 miRNAs from three different cell types are given in Supplementary Table SII. The Pearson correlation coefficient of $\mathrm{R}^{2}=0.9624$ between T3MF and T3CM cells indicates their very similar miRNA expression profiles (Fig. 1C), while no correlation $\left(\mathrm{R}^{2}=0.0043\right)$ was found between T3BA and T3CM cells (Fig. 1D). When the three highly expressed miRNAs miR-199a, miR-372, and miR-302d were excluded from analysis, low correlation $\left(R^{2}=0.3541\right)$ was still observed for the remaining 247 miRNAs of T3BA and T3CM cells (Supplementary Fig. S2). These results indicate that four hES cell-specific miRNAs (miR-372, miR-302d, miR-367, and miR-200c) and three other miRNAs (miR-199a, miR-217, and miR-19a) were over-expressed in T3BA cells, whereas five miRNAs (miR-19b, miR-221, miR-222, let-7b, and let-7c) were underexpressed in T3BA cells compared with T3CM cells (Table I, Fig. 1D and Supplementary Fig. S2).

\section{TARGET IDENTIFICATION OF miRNAs OVER- AND UNDER-EXPRESSED IN T3BA CELLS}

The potential targets of four hES cell-specific miRNAs miR-372, miR-302d, miR-367, and miR-200c, as well as three other overexpressed miRNAs miR-19a, miR-199a, and miR-217, were predicted by the union of miRanda, PicTar (4-way) and TargetScanS with a cut-off $P$-value less than 0.05. The expression levels of these seven miRNAs and their 13 target mRNAs were found to exhibit

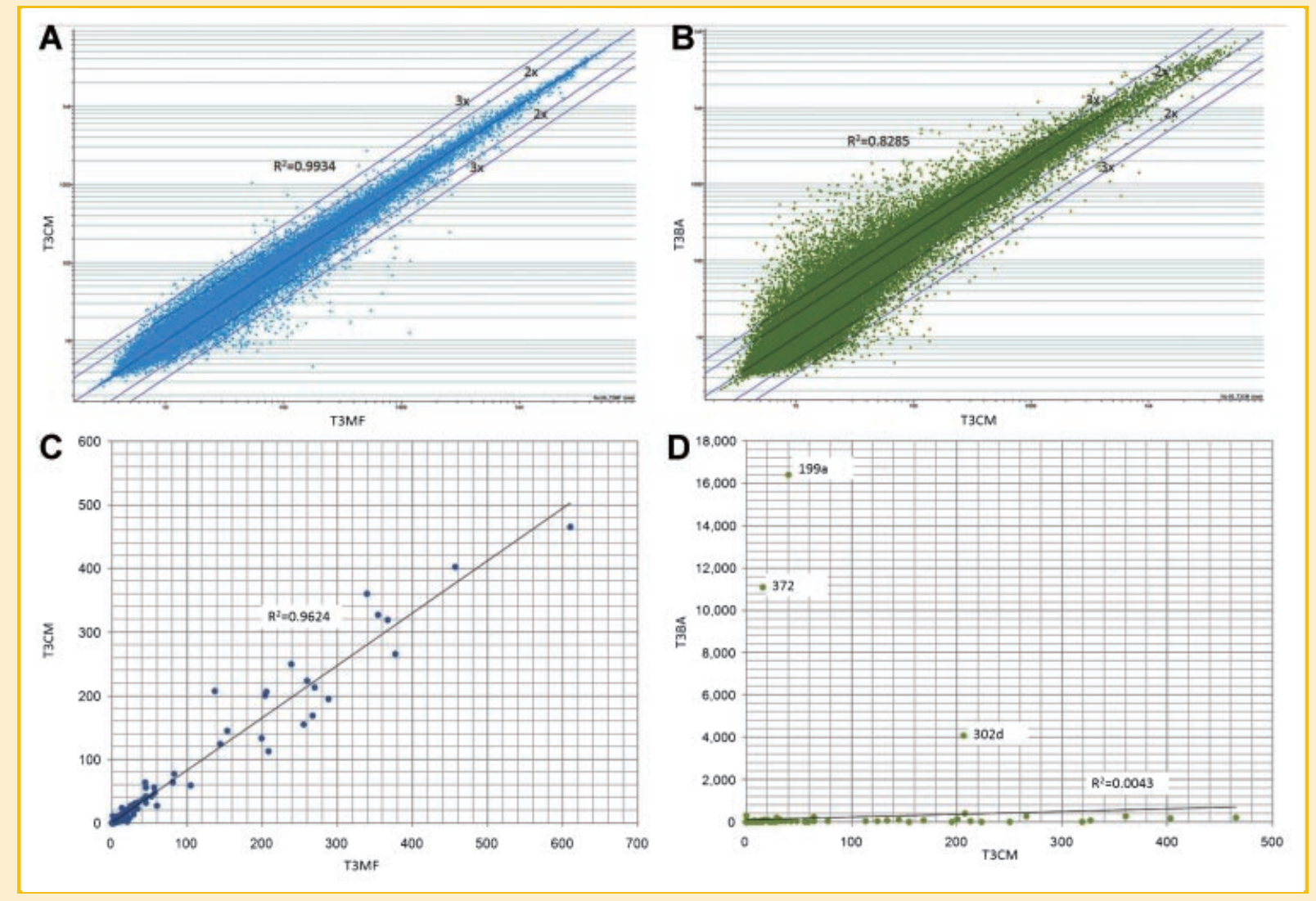

Fig. 1. Scatter plot and correlation analyses of mRNAs and miRNAs among T3MF, T3CM, and T3BA cells. A: $m R N A s$ of T3MF and T3CM; $B$ : $m R N A s$ of T3BA and T3CM; C: miRNAs of T3MF and T3CM; D: miRNAs of T3BA and T3СM. [Color figure can be viewed in the online issue, which is available at www.interscience.wiley.com.] 
TABLE I. Levels of miRNAs Expressed Highly in T3MF, T3CM, and T3BA Cells

\begin{tabular}{|c|c|c|c|c|c|c|c|}
\hline miRs & $\mathrm{T} 3 \mathrm{MF}^{*}$ & T3CM* & T3BA* & $\mathrm{BA} / \mathrm{CM}$ & $\mathrm{CM} / \mathrm{BA}$ & Specificity & Chromosome \\
\hline \multicolumn{8}{|c|}{ A group (up-regulated) } \\
\hline hsa-miR-372 & 27.97 & 15.65 & 11079.38 & 707.9 & 0.0 & hES & $19 q 13.42$ \\
\hline hsa-miR-302d & 205.43 & 206.53 & 4071.21 & 19.7 & 0.1 & hES & $4 q 25$ \\
\hline hsa-miR-367 & 136.63 & 207.63 & 397.69 & 1.9 & 0.5 & hES & $4 q 25$ \\
\hline hsa-miR-200c & 27.76 & 28.94 & 201.26 & 7.0 & 0.1 & hES & $12 \mathrm{p} 13.31$ \\
\hline hsa-miR-199a & 44.84 & 39.81 & 16380.51 & 411.5 & 0.0 & & $19 \mathrm{p} 13.2,1 \mathrm{q} 24.3$ \\
\hline hsa-miR-217 & 0.00 & 0.01 & 296.13 & 29613.0 & 0.0 & & $2 \mathrm{p} 16.1$ \\
\hline hsa-miR-19a & 43.74 & 63.94 & 233.47 & 3.7 & 0.3 & & $13 q 31.3$ \\
\hline \multicolumn{8}{|c|}{ B group (down-regulated) } \\
\hline hsa-miR-19b & 366.63 & 319.07 & 2.56 & 0.0 & 124.6 & & $13 q 31.3, \mathrm{Xq} 26.2$ \\
\hline hsa-miR-221 & 254.57 & 154.90 & 2.93 & 0.0 & 52.9 & & $\mathrm{Xp} 11.3$ \\
\hline hsa-miR-222 & 287.47 & 195.53 & 6.73 & 0.0 & 29.1 & & $\mathrm{Xp} 11.3$ \\
\hline hsa-let-7b & 259.60 & 223.20 & 12.12 & 0.1 & 18.4 & & $22 \mathrm{q} 13.31$ \\
\hline hsa-let-7c & 237.90 & 250.27 & 15.17 & 0.1 & 16.5 & & $21 \mathrm{q} 21.1$ \\
\hline
\end{tabular}

*Expression level of miRNAs was indicated as folds over U6 snRNA.

TABLE II. Negative Correlation Coefficients of Expression Levels Between Activin A Up-Regulated miRNAs and Their Target mRNAs

\begin{tabular}{|c|c|c|c|c|c|c|c|}
\hline Genes & $\operatorname{miR}-372$ & $\operatorname{miR}-302 d$ & miR-367 & miR-200c & miR-19a & miR-199a & $\operatorname{miR}-217$ \\
\hline NR4A2 & -0.543 & -0.542 & & & -0.458 & & -0.542 \\
\hline ERBB4 & -0.700 & -0.701 & & & -0.766 & & \\
\hline CXCR4 & -0.733 & -0.734 & & & & & \\
\hline PCDH9 & & & -0.997 & & & & \\
\hline TMEFF2 & & & & -0.981 & & & \\
\hline CD24 & & & & & -0.968 & & \\
\hline C0X6A1 & & & & & & -0.999 & \\
\hline TAL1 & -0.935 & -0.934 & & & & & \\
\hline GRIA3 & & & -0.962 & & & & \\
\hline PRDM1 & & & & -0.786 & -0.839 & & \\
\hline MYT1 & & & & -0.967 & -0.940 & & \\
\hline EIF4G2 & & & & & -0.957 & & \\
\hline CHMP4B & & & & & -0.999 & & \\
\hline
\end{tabular}

highly negative correlations (Table II). The expression levels of 13 target mRNAs are given in Table III. Seven abundantly (more than threefold of overall mean) differentially (more than threefold of changes) expressed genes NR4A2, ERBB4, CXCR4, PCDH9, TMEFF2, CD24, and COX6A1, as well as six other genes TAL1, GRIA3, PRDM1, MYT1, EIF4G2, and CHMP4B, were found to be targets of miR-372, miR-302d, miR-367, miR-200c, miR-19a, miR-199a, and/ or miR-217.

The five miRNAs miR-19b, miR-221, miR-222, let-7b, and let-7c were under-expressed in T3BA cells compared with T3CM cells, and their 50 target mRNAs were found to exhibit highly negative correlations (Supplementary Table SIII). The expression levels of these 50 target mRNAs are given in Table IV.

\section{VALIDATION OF NR4A2 AND ERBB4 TARGETS}

The two genes NR4A2 and ERBB4 were chosen to be validated by luciferase assay, since they expressed abundantly (more than fourfold of overall mean in T3CM cells) and highly differentially (more than sevenfold changes of T3CM/T3BA) (Table III), but their inverse correlations between the expression levels of miRNAs and

TABLE III. The Expression Levels of 13 Genes Targeted by the Activin A Up-Regulated miRNAs in T3BA Cells

Gene

\begin{tabular}{|c|c|c|c|c|c|c|c|c|c|c|c|c|}
\hline symbol & $\operatorname{miR}-372$ & $302 d$ & 367 & 200c & $19 \mathrm{a}$ & $199 a$ & 217 & T3MF & T3CM* & T3BA & $\mathrm{CM} / \mathrm{BA}^{*}$ & Gene description \\
\hline NR4A2 & 372 & $302 \mathrm{~d}$ & & & $19 \mathrm{a}$ & & 217 & 1.58 & 8.41 & 1.18 & 7.14 & Nuclear receptor subfamily 4 , group A, member 2 \\
\hline ERBB4 & 372 & $302 \mathrm{~d}$ & & & $19 a$ & & & 16.71 & 4.71 & 0.51 & 9.23 & $\begin{array}{l}\text { v-erb-a erythroblastic leukemia viral oncogene } \\
\text { homolog } 4 \text { (avian) }\end{array}$ \\
\hline CXCR4 & 372 & $302 \mathrm{~d}$ & & & & & & 8.42 & 3.05 & 0.71 & 4.30 & Chemokine (C-X-C motif) receptor 4 \\
\hline PCDH9 & & & 367 & & & & & 4.21 & 3.49 & 0.66 & 5.26 & Protocadherin 9 \\
\hline TMEFF2 & & & & $200 c$ & & & & 6.71 & 7.77 & 2.44 & 3.18 & $\begin{array}{l}\text { transmembrane protein with EGF-like and two } \\
\text { follistatin-like domains } 2\end{array}$ \\
\hline CD24 & & & & & $19 a$ & & & 83.54 & 97.85 & 12.87 & 7.60 & CD24 molecule \\
\hline C0X6A1 & & & & & & $199 \mathrm{a}$ & & 707.70 & 695.50 & 156.90 & 4.43 & Cytochrome $c$ oxidase subunit VIa polypeptide 1 \\
\hline TAL1 & 372 & $302 \mathrm{~d}$ & & & & & & 1.51 & 2.03 & 0.59 & 3.44 & T-cell acute lymphocytic leukemia 1 \\
\hline GRIA3 & & & 367 & & & & & 2.32 & 2.34 & 0.69 & 3.39 & Glutamate receptor, ionotrophic, AMPA 3 \\
\hline PRDM1 & & & & $200 c$ & 19a & & & 4.61 & 2.01 & 0.48 & 4.21 & PR domain containing 1 , with ZNF domain \\
\hline MYT1 & & & & $200 c$ & $19 a$ & & & 1.68 & 2.03 & 0.67 & 3.05 & Myelin transcription factor 1 \\
\hline EIF4G2 & & & & & $19 \mathrm{a}$ & & & 2.20 & 2.57 & 0.79 & 3.24 & Eukaryotic translation initiation factor 4 gamma, 2 \\
\hline CHMP4B & & & & & $19 \mathrm{a}$ & & & 2.57 & 2.28 & 0.51 & 4.52 & Chromatin modifying protein $4 \mathrm{~B}$ \\
\hline
\end{tabular}

*The expression levels of more than twofold of overall mean in T3CM cells, more than threefold changes of T3CM/T3BA, and cut-off $P$-value of 0.05 . 
TABLE IV. Expression Levels of 50 Genes Targeted by the Activin A Down-Regulated miRNAs in T3BA Cells

\begin{tabular}{|c|c|c|c|c|c|c|c|c|c|c|}
\hline Gene symbol & miR-19b & 221 & 222 & let-7b & 7c & T3MF & T3CM & T3BA & $\mathrm{BA} / \mathrm{CM}$ & Description \\
\hline ACTN1 & $19 \mathrm{~b}$ & & & & & 0.36 & 0.38 & 3.03 & 7.96 & Actinin, alpha 1 \\
\hline ADRB2 & & & & $7 \mathrm{~b}$ & $7 \mathrm{c}$ & 1.18 & 1.00 & 3.42 & 3.41 & Adrenergic, beta-2-, receptor, surface \\
\hline AMMECR1 & & & & & $7 \mathrm{c}$ & 0.48 & 0.20 & 3.07 & 15.68 & Alport syndrome, mental retardation, gene 1 \\
\hline AMT & & & & $7 \mathrm{~b}$ & & 3.39 & 3.84 & 12.47 & 3.24 & Aminomethyltransferase \\
\hline ARFGEF1 & $19 \mathrm{~b}$ & & & & & 0.92 & 1.05 & 4.28 & 4.07 & ADP-ribosylation factor guanine nucleotide-exchange factor 1 \\
\hline ARIH2 & $19 \mathrm{~b}$ & & & & & 0.43 & 0.34 & 3.66 & 10.87 & Ariadne homolog 2 (Drosophila) \\
\hline ATXN7L1 & $19 \mathrm{~b}$ & & & & & 2.24 & 2.22 & 12.52 & 5.64 & Ataxin 7-like 1 \\
\hline CALB1 & & & & $7 \mathrm{~b}$ & $7 \mathrm{c}$ & 43.90 & 24.57 & 104.40 & 4.25 & Calbindin $1,28 \mathrm{kDa}$ \\
\hline CCND2 & $19 \mathrm{~b}$ & & & $7 \mathrm{~b}$ & $7 \mathrm{c}$ & 0.73 & 0.71 & 3.32 & 4.68 & Cyclin D2 \\
\hline CDC25A & & & & $7 \mathrm{~b}$ & $7 \mathrm{c}$ & 1.39 & 0.66 & 7.21 & 10.93 & Cell division cycle 25 homolog A (S. pombe) \\
\hline CHD7 & & 221 & 222 & $7 \mathrm{~b}$ & $7 \mathrm{c}$ & 0.86 & 0.60 & 3.46 & 5.74 & Chromodomain helicase DNA binding protein 7 \\
\hline CLASP2 & $19 \mathrm{~b}$ & & & $7 \mathrm{~b}$ & $7 \mathrm{c}$ & 0.81 & 0.88 & 3.84 & 4.35 & Cytoplasmic linker associated protein 2 \\
\hline CLASP2 & $19 \mathrm{~b}$ & & & $7 \mathrm{~b}$ & $7 c$ & 0.81 & 0.94 & 3.06 & 3.26 & Cytoplasmic linker associated protein 2 \\
\hline COIL & & & & $7 \mathrm{~b}$ & $7 \mathrm{c}$ & 0.63 & 0.43 & 3.20 & 7.46 & Coilin \\
\hline CPNE8 & & 221 & 222 & & & 0.71 & 0.63 & 3.65 & 5.81 & Copine VIII \\
\hline DACH1 & & 221 & 222 & & & 3.10 & 3.01 & 18.40 & 6.11 & Dachshund homolog 1 (Drosophila) \\
\hline DTNA & $19 \mathrm{~b}$ & & & & & 1.27 & 1.38 & 5.86 & 4.26 & Dystrobrevin, alpha \\
\hline EFNB2 & $19 \mathrm{~b}$ & & & & & 0.24 & 0.14 & 3.80 & 28.16 & Ephrin-B2 \\
\hline EIF2C1 & $19 \mathrm{~b}$ & & & $7 \mathrm{~b}$ & $7 c$ & 0.46 & 0.55 & 8.29 & 15.10 & Eukaryotic translation initiation factor 2C, 1 \\
\hline FAM46B & $19 \mathrm{~b}$ & & & & & 10.11 & 10.23 & 35.74 & 3.49 & Family with sequence similarity 46 , member B \\
\hline FIGN & $19 \mathrm{~b}$ & & & & 7c & 0.30 & 0.26 & 4.50 & 17.36 & Fidgetin \\
\hline FRS2 & $19 \mathrm{~b}$ & 221 & & & & 0.61 & 0.63 & 3.00 & 4.74 & Fibroblast growth factor receptor substrate 2 \\
\hline GRSF1 & $19 \mathrm{~b}$ & & & & & 1.09 & 1.11 & 3.35 & 3.03 & G-rich RNA sequence binding factor 1 \\
\hline GULP1 & $19 \mathrm{~b}$ & & & & & 1.00 & 0.92 & 3.15 & 3.43 & GULP, engulfment adaptor PTB domain containing 1 \\
\hline HIC2 & & & & $7 \mathrm{~b}$ & $7 \mathrm{c}$ & 0.54 & 0.15 & 3.80 & 25.34 & Hypermethylated in cancer 2 \\
\hline ILF3 & $19 \mathrm{~b}$ & & & & & 0.97 & 0.62 & 3.35 & 5.42 & Interleukin enhancer binding factor 3, 90kDa \\
\hline KCMF1 & $19 \mathrm{~b}$ & 221 & 222 & & & 1.07 & 1.03 & 3.79 & 3.67 & Potassium channel modulatory factor 1 \\
\hline KLF13 & $19 \mathrm{~b}$ & & & & & 0.89 & 0.70 & 4.54 & 6.48 & Kruppel-like factor 13 \\
\hline KRAS & $19 \mathrm{~b}$ & & & & & 0.71 & 0.56 & 3.38 & 6.02 & v-Ki-ras2 Kirsten rat sarcoma viral oncogene homolog \\
\hline MPPED2 & $19 \mathrm{~b}$ & & & & & 1.48 & 1.63 & 14.63 & 8.97 & Metallophosphoesterase domain containing 2 \\
\hline MYCL1 & $19 \mathrm{~b}$ & & & & & 3.79 & 2.97 & 10.92 & 3.68 & v-myc myelocytomatosis viral oncogene homolog 1 , \\
\hline NAV3 & $19 \mathrm{~b}$ & & & & & 0.51 & 0.82 & 4.37 & 5.35 & Neuron navigator 3 \\
\hline NRG1 & $19 \mathrm{~b}$ & & 222 & & & 1.56 & 1.90 & 6.23 & 3.27 & Neuregulin 1 \\
\hline NRK & $19 \mathrm{~b}$ & 221 & 222 & $7 \mathrm{~b}$ & 7c & 0.82 & 2.86 & 8.66 & 3.03 & Nik-related kinase \\
\hline PCDHA9 & $19 \mathrm{~b}$ & 221 & 222 & & & 1.17 & 1.05 & 6.81 & 6.52 & Protocadherin alpha 9 \\
\hline PGM2L1 & & & & $7 \mathrm{~b}$ & 7c & 0.87 & 1.04 & 3.95 & 3.81 & Phosphoglucomutase 2 -like 1 \\
\hline POGZ & & 221 & 222 & $7 \mathrm{~b}$ & $7 \mathrm{c}$ & 0.98 & 0.69 & 3.14 & 4.54 & Pogo transposable element with ZNF domain \\
\hline PRPF38B & & & & $7 \mathrm{~b}$ & $7 \mathrm{c}$ & 0.31 & 0.21 & 3.17 & 15.47 & PRP38 pre-mRNA processing factor 38 domain containing B \\
\hline PTBP2 & & 221 & & & & 3.50 & 2.51 & 8.45 & 3.37 & Polypyrimidine tract binding protein 2 \\
\hline PTEN & & 221 & & & & 0.74 & 0.82 & 6.39 & 7.82 & Phosphatase and tensin homolog \\
\hline RGS16 & & & & $7 \mathrm{~b}$ & $7 \mathrm{c}$ & 4.64 & 1.43 & 5.11 & 3.56 & Regulator of G-protein signaling 16 \\
\hline SLC1A2 & $19 \mathrm{~b}$ & & 222 & & & 2.44 & 1.31 & 7.26 & 5.54 & Solute carrier family 1 , member 2 \\
\hline SMARCD1 & & & & $7 \mathrm{~b}$ & $7 \mathrm{c}$ & 1.27 & 1.07 & 3.67 & 3.43 & SWI/SNF related, matrix associated, member 1 \\
\hline SOCS1 & $19 \mathrm{~b}$ & & & & & 1.44 & 1.29 & 7.53 & 5.83 & Suppressor of cytokine signaling 1 \\
\hline SOX 4 & $19 \mathrm{~b}$ & & 222 & & & 0.35 & 0.18 & 7.51 & 41.01 & SRY (sex determining region Y)-box 4 \\
\hline STRBP & & & & $7 \mathrm{~b}$ & $7 c$ & 6.24 & 3.47 & 41.99 & 12.10 & Spermatid perinuclear RNA binding protein \\
\hline VANGL2 & & & 222 & $7 \mathrm{~b}$ & & 3.62 & 3.64 & 12.00 & 3.29 & Vang-like 2 (van gogh, Drosophila) \\
\hline VAV3 & $19 \mathrm{~b}$ & & & $7 \mathrm{~b}$ & $7 \mathrm{c}$ & 2.20 & 2.54 & 9.12 & 3.59 & Vav 3 oncogene \\
\hline ZBTB10 & & & & $7 \mathrm{~b}$ & $7 \mathrm{c}$ & 1.76 & 1.15 & 4.12 & 3.60 & Zinc finger and BTB domain containing 10 \\
\hline ZNF518 & $19 \mathrm{~b}$ & & & & & 1.33 & 0.68 & 3.76 & 5.51 & Zinc finger protein 518 \\
\hline
\end{tabular}

target mRNAs were not very high (Table II). The potential miRNA binding sites of the $3^{\prime}$-UTRs of NR4A2 and ERBB4 genes were predicted using PicTar and TargetScanS programs. The $3^{\prime}$-UTR of NR4A2 was found by both methods to contain two potential miR372 binding sites, four miR-302d binding sites and one miR-19a binding site, but miR-217 binding site was predicted by TargetScanS only. The 3'-UTR of ERBB4 was found by both methods to have one site for miR-302d and two sites for miR19a, but miR-372 binding site was predicted by TargetScanS only. The potential binding structures with free energies predicted by PicTar program of both NR4A2 and ERBB4 genes were shown in Supplementary Figure S3A and $\mathrm{S} 3 \mathrm{~B}$, and the base pairing between miRNAs and their target mRNAs, as well as the construction of luciferase reporter vectors, are shown in Figure 2A,B. To demonstrate directly whether NR4A2 and ERBB4 genes were indeed the targets of miR-372, miR-302d, miR19a, and/or miR-217, the luciferase reporter vectors harboring the 3'-UTRs of target genes were co-transfected with pSilencer vector containing miRNAs precursor or not in HET293T cells. The luciferase activity of reporter vector harboring NR4A2 3'-UTR was inhibited to $37 \%, 38 \%$, 53\%, or 33\% by miR-372, miR-302d, miR-19a, or miR217 , respectively. In the case of ERBB4, the luciferase activity was suppressed to $58 \%, 74 \%$, or $81 \%$ by miR-372, miR-302d, or miR19a, respectively (Fig. 2C). These results implied that NR4A2 gene was inhibited much stronger than ERBB4 gene by miR-372, miR302d, and miR-19a, although NR4A2 gene exhibited lower reverse correlations $(-0.46$ to -0.54$)$ between the expression of its mRNA and those of miRNAs (Table II).

\section{ANALYSES OF NETWORK AND SIGNALING PATHWAYS}

The mRNAs expressed more than threefold of overall mean from T3BA and T3CM cells were also analyzed for the network and signaling pathways by using MetaCore Analytical Suite. Besides 969 common genes, 1,396 and 153 genes were found to be unique for T3BA and T3CM cells, respectively (Fig. 3A), and the top 3 scored 


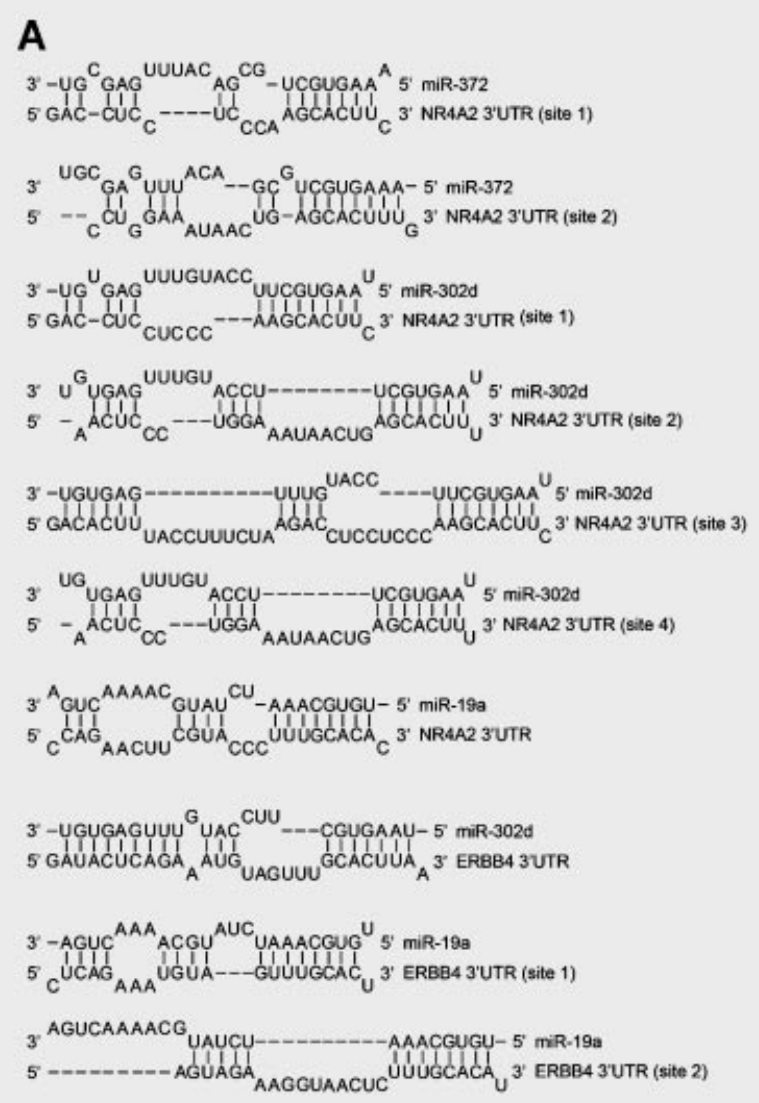

B
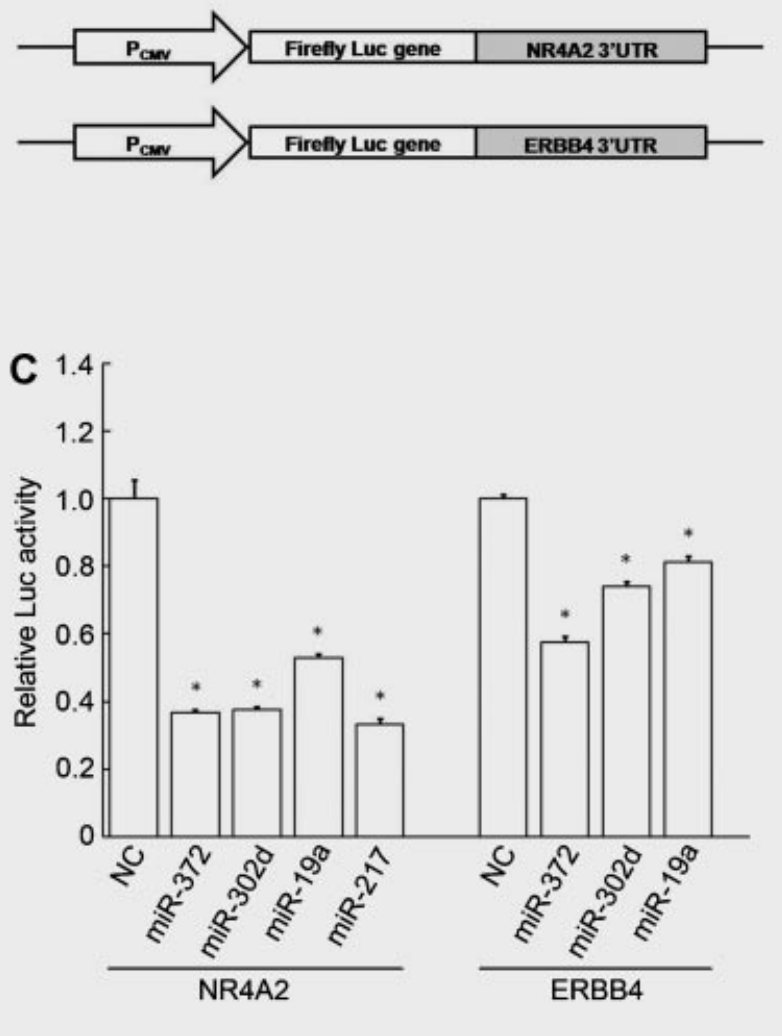

Fig. 2. Leuciferase experiments to validate NR4A2 and ERBB4 targets. A: Predicted binding sites of miR-372, miR-302d, and miR-19a within the $3^{\prime}-U T R s$ of NR4A2 and ERBB4. The base-pairings were indicated by short vertical lines between miRNAs and $3^{\prime}-U T R s$ of target genes. B: The construction of luciferase reporter vectors. C: The effects of miR-372, miR-302d, miR-19a, and/or miR-217 on the luciferase activity of NR4A2 and ERBB4 reporter vectors. HEK293T cells were co-transfected with the reporter vector and miRNAs (as indicated), and luciferase activities were measured $48 \mathrm{~h}$ later. Shown are means with SE values. ${ }^{*} P$ is less than 0.0001 when compared with mock control (reporter vector co-transfected with negative control miRNA, NC). [Color figure can be viewed in the online issue, which is available at www.interscience.wiley.com.]

pathways (with lowest $P$-value) involved in regulation of cell cycle were highly regulated by activin A (Fig. 3B). The roles of activin A in cell differentiation and proliferation, and the expression levels of induced genes are given in Supplementary Figure S4 and Table SIV, respectively. Activin A through its receptor ActR2B increased the expression of OCT4 and NANOG, as well as LEFTY-1 and LEFTY-2, to regulate stem cell maintenance. The abundantly differentially expressed target genes NR4A2, ERBB4, and CXCR4 of miRNAs miR372, miR-302d, miR-19a, and/or miR-217 highly induced by activin A in T3BA cells were also analyzed using IPA for their involvements in network and signaling pathways. The NR4A2 in nucleus and CXCR4 associated with plasma membrane were found to be commonly regulated by both EGF and TNF, while the membrane associated ERBB4 is regulated by EGF only (Supplementary Fig. S5).

\section{DISCUSSION}

The expression profiles of both mRNAs and miRNAs from T3MF and T3CM cells were shown to be very similar (Fig. 1A,C), indicating that the unlimited self-renewal and pluripotency of hES-T3 cells can be maintained by continuous culture on either MEF feeder in hES medium (containing $4 \mathrm{ng} / \mathrm{ml} \mathrm{bFGF}$ ) or feeder-free Matrigel in MEFconditioned medium (containing additional $4 \mathrm{ng} / \mathrm{ml} \mathrm{bFGF}$ ). When $\mathrm{hES}$-T3 cells were grown on feeder-free Matrigel in hES medium (without bFGF) supplemented with 5,10 , and $25 \mathrm{ng} / \mathrm{ml}$ activin A, many cells around the edges, as well as the center, of colonies differentiated into fibroblast-like cells with much less staining of OCT4 and NANOG, and these hES-T3 cells were able to proliferate only two more passages, indicating that $\mathrm{bFGF}$ is indispensable for maintenance of self-renewal of hES cells. The T3BA cells grown on the feeder-free Matrigel in hES medium containing $4 \mathrm{ng} / \mathrm{ml} \mathrm{bFGF}$ and $5 \mathrm{ng} / \mathrm{ml}$ activin A were able to maintain their undifferentiated proliferation for seven more passages. However, the expression profiles, especially miRNAs, of T3BA cells were found to be very different from those of T3MF and T3CM cells, indicating that both bFGF and activin A are not sufficient for maintenance of selfrenewal of hES cells. These results are in contrast to the previous report that activin A was necessary and sufficient for the maintenance of self-renewal and pluripotency of hES cells in 


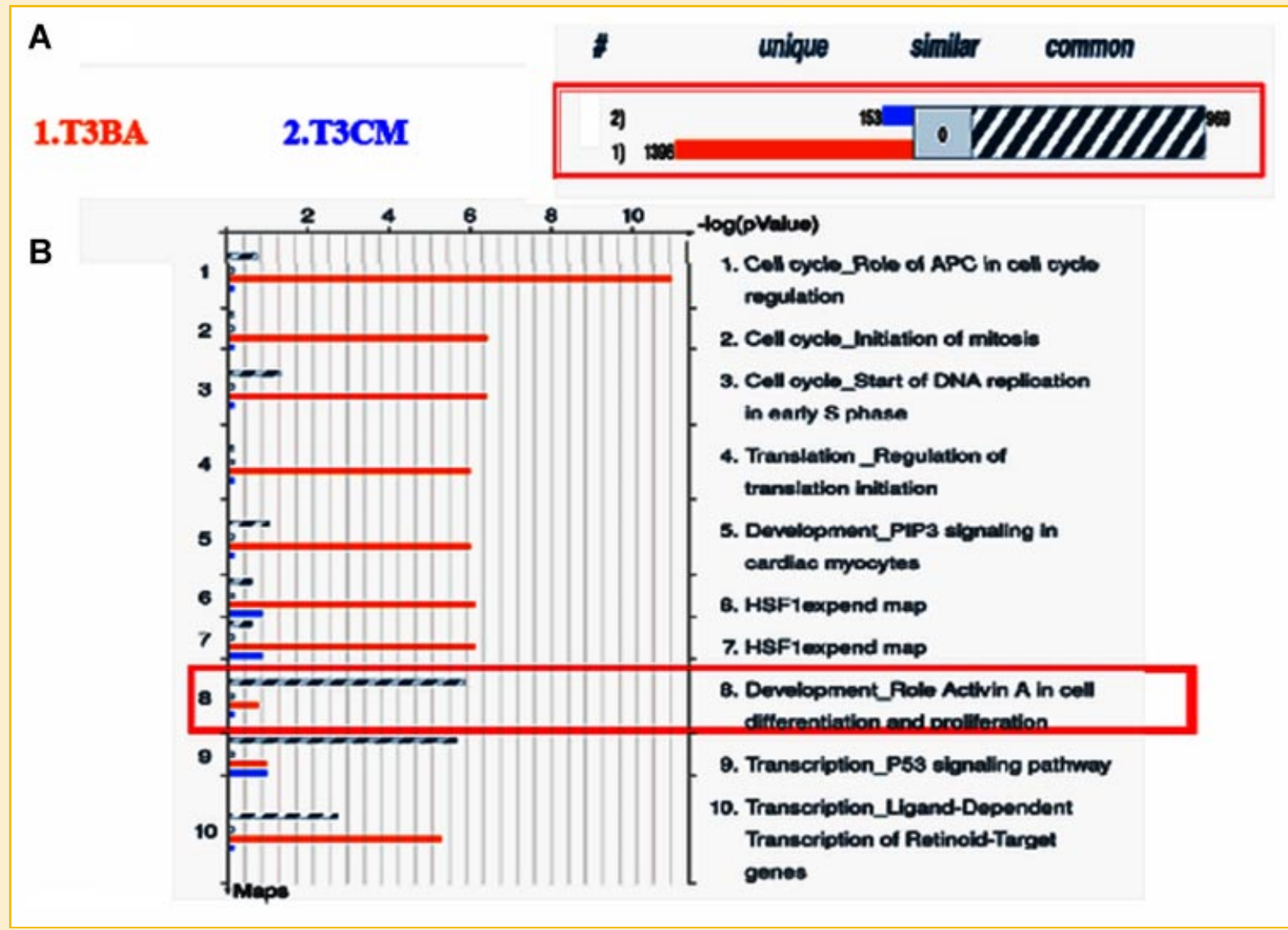

Fig. 3. Comparison of gene expression and GeneGo canonical pathway maps among T3CM and T3BA cells. A: The parameters for comparison are set at threshold of 3 with $P$ value of 0.05 . The common genes are indicated by blue/white strips. The unique genes are marked as color band: (1) T3BA, orange; (2) T3CM, blue. B: The top $10 \mathrm{GeneGo}$ canonical pathway maps among T3BA and T3CM cells. The degree of "relevance" to different GeneGo ontology categories is defined by $P$-value, so that the lower random $P$ value gets higher priority. [Color figure can be viewed in the online issue, which is available at www.interscience.wiley.com.]

long-term feeder- and serum-free culture [Xiao et al., 2006]. Activin A has been reported to inhibit cell proliferation and activate cell differentiation, although it was also shown to participate in maintenance of pluripotency, possibly, via SMAD-dependent activation transcription of OCT4, NANOG, NODAL, and NODALsignaling regulators LEFTY-1 and LEFTY-2 [Beattie et al., 2005; James et al., 2005]. The activin A induced differentiation of hES-T3 cells was probably due to the induced expression of PBX1 and CREB1 (Supplementary Fig. S4 and Table SIV).

The seven miRNAs miR-372, miR-302d, miR-367, miR-200c, miR-19a, miR-199a, and miR-217 were found to be highly upregulated by activin A in T3BA cells (Table I, Fig. 1D, and Supplementary Fig. S2). The expression of hES cell-specific miR302 cluster was previously shown to be regulated by OCT4 and SOX2 [Card et al., 2008]. Thus, activin A through its receptor ActR2B increased indirectly the expression of 0CT4 to induce the expression of hES cell-specific miR-372, miR-302d, miR-367, and miR-200c. The miR-199a was found to be most abundant in T3BA cells, and its target C0X6A1 expressed extremely abundantly in T3MF and T3CM cells was down-regulated inT3BA cells. The miR-199a is encoded by duplicated genes located within the intron of dynamin genes on chromosomes 1 and 19. Since the miR-199a genes are positioned in opposite direction to the dynamin genes, they may be transcribed from their own promoters. The expression of miR-199a was also reported to be controlled by transcription factor TWIST-1 via an Ebox promoter element [Lee et al., 2009], and how activin A indirectly regulate TWIST-1 remains to be elucidated. It may be noted that miR-199a and miR-199a* (processed from the same miRNA precursor) were recently reported to down-regulate the MET proto-oncogene and its downstream effector extracellular signalregulated kinase 2 (ERK2) gene resulting in inhibiting cell proliferation of tumor cells [Kim et al., 2008]. The miR-199a and miR-199a* were also shown to inhibit the mRNA translation of IкB kinase $\beta$ required for NF- $\kappa \mathrm{B}$ activation in ovarian cancer cells [Chen et al., 2008]. The miR-217 was also found to be highly expressed in T3BA, but not at all in T3MF and T3CM cells (Table I). It is of interest that the miR-217 was reported to be linked to tumorigenesis in pancreatic ductal adenocarcinoma [Szafranska et al., 2007] and used as one of biomarkers to discriminate benign and malignant pancreatic tissues [Szafranska et al., 2008].

The abundantly differentially expressed genes NR4A2, ERBB4, and CXCR4 were shown to be targets of miRNAs miR-372, miR302d, miR-19a, and/or miR-217 highly induced by activin A in T3BA cells. The NR4A2 and CXCR4 were further found to be 
commonly regulated by both EGF and TNF, while the ERBB4 was regulated by EGF only (Supplementary Fig. S5). It may be noted that the NR4A2, as well as TMEFF2 and TAL1, was also included in the previously reported 58 target genes of hES cell-specific miR-372, miR-302d, miR-367, and/or miR-200c [Li et al., 2009]. The luciferase assay in this investigation confirmed that the $3^{\prime}$-UTRs of both NR4A2 and ERBB4 genes indeed contain the target sites of miR-372, miR-302d, miR-19a, and/or miR-217, resulting in their mRNA destablilization and/or translational inhibition.

The NR4A2, also known as NURR1, is essential for the differentiation of the midbrain dopaminergic neurons, and it was reported to cooperate with PITX3 in promoting the terminal maturation of human and murine embryonic stem cell cultures to a dopamine neuron phenotype, and neither factor alone induced differentiation [Martinat et al., 2006]. The ERBB4 is a transmembrane receptor tyrosine kinase that regulates cell proliferation and differentiation. The ERBB4 and its ligand heregulin are essential for neuronal development. The ERBB4 was reported to express at high levels in rat subventricular zone and rostral migratory system and to play a role in neuroblast tangential migration and olfactory interneuronal placement [Anton et al., 2004]. The CXCR4, a chemokine receptor, is a crucial effector of the transcriptional pathway specifying mouse ventral motor neurons, and it controls the precision of initial motor axon trajectories [Lieberam et al., 2005]. The CXCR4 has also been used as a biomarker of definite endoderm which is induced by activin A.

\section{ACKNOWLEDGMENTS}

We thank Dr. Chien-Chih Chiu and Bai Hsun Chen as co-mentors to Z.Y. Tsai and B.Z. Chen, respectively. We also thank the technical assistance by the research assistants at Microarray Core Facility of National Research Program for Genomic Medicine of National Science Council in Taiwan.

\section{REFERENCES}

Alvarez-Garcia I, Miska EA. 2005. MicroRNA functions in animal development and human disease. Development 132:4653-4662.

Anton ES, Ghashghaei HT, Weber JL, McCann C, Fischer TM, Cheung ID, Gassmann M, Messing A, Klein R, Schwab MH, Lloyd KC, Lai C. 2004. Receptor tyrosine kinase ErbB4 modulates neuroblast migration and placement in the adult forebrain. Nat Neurosci 7:1319-1328.

Baek D, Villen J, Shin C, Camargo FD, Gygi SP, Bartel DP. 2008. The impact of microRNAs on protein output. Nature 455:64-71.

Bagga S, Bracht J, Hunter S, Massirer K, Holtz J, Eachus R, Pasquinelli AE. 2005. Regulation by let-7 and lin-4 miRNAs results in target mRNA degradation. Cell 122:553-563.

Bartel DP. 2004. MicroRNAs: Genomics, biogenesis, mechanism, and function. Cell 116:281-297.

Beattie GM, Lopez AD, Bucay N, Hinton A, Firpo MT, King CC, Hayek A. 2005. Activin A maintains pluripotency of human embryonic stem cells in the absence of feeder layers. Stem Cells 23:489-495.

Canales RD, Luo Y, Willey JC, Austermiller B, Barbacioru CC, Boysen C, Hunkapiller K, Jensen RV, Knight CR, Lee KY, Ma Y, Maqsodi B, Papallo A, Peters EH, Poulter K, Ruppel PL, Samaha RR, Shi L, Yang W, Zhang L, Goodsaid FM. 2006. Evaluation of DNA microarray results with quantitative gene expression platforms. Nat Biotechnol 24:1115-1122.
Card DA, Hebbar PB, Li L, Trotter KW, Komatsu Y, Mishina Y, Archer TK. 2008. 0ct4/Sox2-regulated miR-302 targets cyclin D1 in human embryonic stem cells. Mol Cell Biol 28:6426-6438.

Chen C, Ridzon DA, Broomer AJ, Zhou Z, Lee DH, Nguyen JT, Barbisin M, Xu NL, Mahuvakar VR, Andersen MR, Lao KQ, Livak KJ, Guegler KJ. 2005. Realtime quantification of microRNAs by stem-loo p RT-PCR. Nucleic Acids Res 33:e179.

Chen C, Ridzon D, Lee CT, Blake J, Sun Y, Strauss WM. 2007. Defining embryonic stem cell identity using differentiation-related microRNAs and their potential targets. Mamm Genome 18:316-327.

Chen R, Alvero AB, Silasi DA, Kelly MG, Fest S, Visintin I, Leiser A, Schwartz PE, Rutherford T, Mor G. 2008. Regulation of IKKbeta by miR-199a affects NF-kappaB activity in ovarian cancer cells. Oncogene 27:4712-4723.

Farh KK, Grimson A, Jan C, Lewis BP, Johnston WK, Lim LP, Burge CB, Bartel DP. 2005. The widespread impact of mammalian MicroRNAs on mRNA repression and evolution. Science 310:1817-1821.

Griffiths-Jones S, Grocock RJ, van Dongen S, Bateman A, Enright AJ. 2006. miRBase: MicroRNA sequences, targets and gene nomenclature. Nucleic Acids Res 34:D140-D144.

Guhr A, Kurtz A, Friedgen K, Loser P. 2006. Current state of human embryonic stem cell research: An overview of cell lines and their use in experimental work. Stem Cells 24:2187-2191.

Houbaviy HB, Murray MF, Sharp PA. 2003. Embryonic stem cell-specific MicroRNAs. Dev Cell 5:351-358.

James D, Levine AJ, Besser D, Hemmati-Brivanlou A. 2005. TGFbeta/activin/ nodal signaling is necessary for the maintenance of pluripotency in human embryonic stem cells. Development 132:1273-1282.

John B, Enright AJ, Aravin A, Tuschl T, Sander C, Marks DS. 2004. Human MicroRNA targets. PLoS Biol 2:e363.

Kim S, Lee UJ, Kim MN, Lee EJ, Kim JY, Lee MY, Choung S, Kim YJ, Choi YC. 2008. MicroRNA miR-199a* regulates the MET proto-oncogene and the downstream extracellular signal-regulated kinase 2 (ERK2). J Biol Chem 283:18158-18166.

Kloosterman WP, Plasterk RH. 2006. The diverse functions of microRNAs in animal development and disease. Dev Cell 11:441-450.

Laurent LC, Chen J, Ulitsky I, Mueller FJ, Lu C, Shamir R, Fan JB, Loring JF. 2008. Comprehensive microRNA profiling reveals a unique human embryonic stem cell signature dominated by a single seed sequence. Stem Cells 26:1506-1516.

Lee YB, Bantounas I, Lee DY, Phylactou L, Caldwell MA, Uney JB. 2009. Twist-1 regulates the miR-199a/214 cluster during development. Nucleic Acids Res 37:123-128.

Li SS, Liu YH, Tseng CN, Chung TL, Lee TY, Singh S. 2006. Characterization and gene expression profiling of five new human embryonic stem cell lines derived in Taiwan. Stem Cells Dev 15:532-555.

Li SS, Yu SL, Kao LP, Tsai ZY, Singh S, Chen BZ, Ho BC, Liu YH, Yang PC. 2009. Target identification of microRNAs expressed highly in human embryonic stem cells. J Cell Biochem 106:1020-1030.

Liang Y, Ridzon D, Wong L, Chen C. 2007. Characterization of microRNA expression profiles in normal human tissues. BMC Genomics 8:166.

Lieberam I, Agalliu D, Nagasawa T, Ericson J, Jessell TM. 2005. A Cxcl12CXCR4 chemokine signaling pathway defines the initial trajectory of mammalian motor axons. Neuron 47:667-679.

Lim LP, Lau NC, Garrett-Engele P, Grimson A, Schelter JM, Castle J, Bartel DP, Linsley PS, Johnson JM. 2005. Microarray analysis shows that some microRNAs downregulate large numbers of target mRNAs. Nature 433:769773.

Martinat C, Bacci JJ, Leete T, Kim J, Vanti WB, Newman AH, Cha JH, Gether $\mathrm{U}$, Wang $\mathrm{H}$, Abeliovich A. 2006. Cooperative transcription activation by Nurr1 and Pitx 3 induces embryonic stem cell maturation to the midbrain dopamine neuron phenotype. Proc Natl Acad Sci USA 103:2874-2879. 
Mayr C, Hemann MT, Bartel DP. 2007. Disrupting the pairing between let-7 and Hmga2 enhances oncogenic transformation. Science 315:1576-1579.

Selbach M, Schwanhausser B, Thierfelder N, Fang Z, Khanin R, Rajewsky N. 2008. Widespread changes in protein synthesis induced by microRNAs. Nature 455:58-63.

Sethupathy P, Megraw M, Hatzigeorgiou AG. 2006. A guide through present computational approaches for the identification of mammalian microRNA targets. Nat Methods 3:881-886.

Shi L, Reid LH, Jones WD, Shippy R, Warrington JA, Baker SC, Collins PJ, de Longueville F, Kawasaki ES, Lee KY, Luo Y, Sun YA, Willey JC, Setterquist RA, Fischer GM, Tong W, Dragan YP, Dix DJ, Frueh FW, Goodsaid FM, Herman D, Jensen RV, Johnson CD, Lobenhofer EK, Puri RK, Schrf U, Thierry-Mieg J, Wang C, Wilson M, Wolber PK, Zhang L, Amur S, Bao W, Barbacioru CC, Lucas AB, Bertholet V, Boysen C, Bromley B, Brown D, Brunner A, Canales R, Cao XM, Cebula TA, Chen JJ, Cheng J, Chu TM, Chudin E, Corson J, Corton JC, Croner LJ, Davies C, Davison TS, Delenstarr G, Deng X, Dorris D, Eklund AC, Fan XH, Fang H, Fulmer-Smentek S, Fuscoe JC, Gallagher K, Ge W, Guo L, Guo X, Hager J, Haje PK, Han J, Han T, Harbottle HC, Harris SC, Hatchwell E, Hauser CA, Hester S, Hong H, Hurban P, Jackson SA, Ji H, Knight CR, Kuo WP, LeClerc JE, Levy S, Li QZ, Liu C, Liu Y, Lombardi MJ, Ma Y, Magnuson SR, Maqsodi B, McDaniel T, Mei N, Myklebost 0, Ning B, Novoradovskaya N, Orr MS, Osborn TW, Papallo A, Patterson TA, Perkins RG, Peters EH, Peterson R, et al. 2006. The MicroArray Quality Control (MAQC) project shows inter- and intraplatform reproducibility of gene expression measurements. Nat Biotechnol 24:1151-1161.

Sood P, Krek A, Zavolan M, Macino G, Rajewsky N. 2006. Cell-type-specific signatures of microRNAs on target mRNA expression. Proc Natl Acad Sci USA 103:2746-2751.
Stark A, Brennecke J, Bushati N, Russell RB, Cohen SM. 2005. Animal MicroRNAs confer robustness to gene expression and have a significant impact on 3'UTR evolution. Cell 123:1133-1146.

Suh MR, Lee Y, Kim JY, Kim SK, Moon SH, Lee JY, Cha KY, Chung HM, Yoon HS, Moon SY, Kim VN, Kim KS. 2004. Human embryonic stem cells express a unique set of microRNAs. Dev Biol 270:488-498.

Szafranska AE, Davison TS, John J, Cannon T, Sipos B, Maghnouj A, Labourier E, Hahn SA. 2007. MicroRNA expression alterations are linked to tumorigenesis and non-neoplastic processes in pancreatic ductal adenocarcinoma. Oncogene 26:4442-4452.

Szafranska AE, Doleshal M, Edmunds HS, Gordon S, Luttges J, Munding JB, Barth RJ, Jr., Gutmann EJ, Suriawinata AA, Marc Pipas J, Tannapfel A, Korc M, Hahn SA, Labourier E, Tsongalis GJ. 2008. Analysis of microRNAs in pancreatic fine-needle aspirates can classify benign and malignant tissues. Clin Chem 54:1716-1724.

Thomson JA, Itskovitz-Eldor J, Shapiro SS, Waknitz MA, Swiergiel JJ, Marshall VS, Jones JM. 1998. Embryonic stem cell lines derived from human blastocysts. Science 282:1145-1147.

Wobus AM, Boheler KR. 2005. Embryonic stem cells: Prospects for developmental biology and cell therapy. Physiol Rev 85:635-678.

Xiao L, Yuan X, Sharkis SJ. 2006. Activin A maintains self-renewal and regulates fibroblast growth factor, Wnt, and bone morphogenic protein pathways in human embryonic stem cells. Stem Cells 24:1476-1486.

Xu C, Inokuma MS, Denham J, Golds K, Kundu P, Gold JD, Carpenter MK. 2001. Feeder-free growth of undifferentiated human embryonic stem cells. Nat Biotechnol 19:971-974. 